\title{
The nutraceutical effect of Scenedesmus dimorphus for obesity and nonalcoholic fatty liver disease-linked metabolic syndrome
}

\author{
Armaini Armaini*, Abdi Dharma, Marniati Salim \\ Department of Chemistry, Biochemistry Laboratory, Faculty of Mathematics and Natural Sciences, Andalas University, Padang 25163, Indonesia.
}

\section{ARTICLE INFO \\ Received on: 20/04/2019 \\ Accepted on: 16/12/2019 \\ Available online: 06/05/2020}

Key words:

Obesity, NAFLD, metabolic

syndrome, lipid profile,

Scenedesmus dimorphus.

\begin{abstract}
Obesity is a major cause of nonalcoholic fatty liver disease (NAFLD), which is identified as a characteristic related to metabolic syndrome. This study focuses on the benefits of Scenadesmus dimorphus as a nutraceutical to overcome NAFLD-linked metabolic syndrome caused by obesity. The research used 30 mice (Mus musculus) divided into six groups: normal control, obesity control (OC), and drug control (Orlistat) and $S$. dimorphus administrated orally for 21 days in obese mice with NAFLD-linked metabolic syndrome with doses of $5 \mathrm{mg} / 20 \mathrm{~g}$ body weight (BW), 10 $\mathrm{mg} / 20 \mathrm{~g} \mathrm{BW}$, and $15 \mathrm{mg} / 20 \mathrm{~g} \mathrm{BW}$. The administration of a high-fat diet can cause obese mice to suffer from NAFLD, resulting in an increase in liver enzymes and changes in lipid metabolism. Administration of $S$. dimorphus at 15 $\mathrm{mg} / 20 \mathrm{~g} \mathrm{BW}$ decreases the activity of liver enzymes and improves liver function. The statistics test showed significant differences ( $p<0.05$ analysis of variance) to decrease the liver enzyme activity of alanine aminotransferase, aspartate aminotransferase, and alkaline phosphatase compared to OCs. Administration of S. dimorphus resulting in metabolism changes showed a significant (at $p<0.05$ ) decrease in total cholesterol, triglycerides, and low-density lipoprotein cholesterol and increased high-density lipoprotein cholesterol. Microalgae S. dimorphus is beneficial as a nutraceutical to manage obesity and reverse NAFLD-linked metabolic syndrome in obese mice.
\end{abstract}

\section{INTRODUCTION}

The prevalence of obesity is currently receiving widespread attention globally, as it is the most common cause of chronic liver disease in almost all countries, especially in Indonesia (WHO, 2017). The prevalence of NAFLD in children and adolescents from the general population study was $7.6 \%(95 \%$ CI: $5.5 \%$ to $10 \%$ ) and $34.2 \%$ based on clinical studies in obese children with NAFLD (95\% CI: $27.9 \%$ to $41.2 \%$ ). Prevalence is higher in men than in women and increases gradually with greater body mass index (BMI) (Anderson et al., 2015).

Obesity in childhood is associated with a greater likelihood of hepatocellular carcinoma as an adult. NAFLD suffered by children due to obesity can develop into advanced fibrosis $(10 \%-25 \%)$; in more severe cases, it can develop into

\section{"Corresponding Author}

Armaini Armaini, Department of Chemistry, Biochemistry Laboratory, Faculty of Mathematics, and Natural Sciences, Andalas University, Padang 25163, Indonesia.E-mail: armaini59@gmail.com cirrhosis and high-stage liver disease (Goyal and Schwimmer, 2016). Based on research conducted in the United States, out of 6,000 people tested, $30 \%$ suffered from NAFLD and 10\% suffered from advanced fibrosis. The risk of death at 5-8 years in NAFLD subjects with advanced fibrosis was significantly higher than in subjects without NAFLD (18\% to $35 \%$ vs. $2.6 \%$ to $5.5 \%$ ) (Le et al., 2017). Studies conducted in the community in the United States on the trend of NAFLD and the impact on the incidence of metabolic comorbidities, cardiovascular (CV) were higher in NAFLD patients and mortality over a period of 20 years showed that in general, NAFLD in the community increased five-fold, especially in young adults (18-39) years old seven-fold increases (Allen et al., 2018). The research was conducted on populations from two countries, Saudi Arabia and the United Arab Emirates. The study was conducted to predict the progression of NAFLD and nonalcoholic steatohepatitis (NASH) disease based on the prevalence of adults suffering from obesity and diabetes mellitus in both countries. The prevalence of NAFLD increases parallel to the projected increase in obesity and diabetes mellitus and is predicted to double in 2030 (Alswat et al., 2018). 
Obesity is one of the main causes of nonalcoholic fatty liver disease (NAFLD). NAFLD covers almost all liver diseases such as simple steatosis for alcoholic steatohepatitis (NASH) and subsequently becomes noncholestatic cirrhosis and hepatocellular carcinoma. Steatosis is associated with fatty acids (FAs), lipoprotein metabolism, and abnormalities in FA metabolism, which are associated with adipose tissue, liver, and systemic inflammation. This is a key factor involved in the development of insulin resistance, dyslipidemia, and other cardiometabolic risk factors associated with NAFLD (Fabbrini et al., 2010). NAFLD is strongly associated with several metabolic disorders and diseases such as obesity, type 2 diabetes mellitus, and dyslipidemia. NAFLD and dyslipidemia manifested as an increase in serum triglycerides (TG), cholesterol levels, and low-density lipoprotein (LDL) cholesterol and a decrease in high-density lipoprotein (HDL) cholesterol, a major risk factor of heart disease (cardiovascular Diseases) (Zhang and $\mathrm{Lu}, 2015)$. The pathological sign of NAFLD is lipid accumulation in hepatocytes, suggesting that there is a close relationship between abnormal lipid metabolism and NAFLD. The majority of patients with NAFLD have metabolic syndrome (Dima et al., 2012), so it is considered a liver manifestation of metabolic syndrome (Ji et al., 2014). The role of obesity, type 2 diabetes mellitus (T2DM), and dyslipidemia in the pathogenesis of NAFLD is an important component of metabolic syndrome. Changes in metabolic profiles due to obesity increase serum lipid levels (dyslipidemia) affect type 2 diabetes mellitus and metabolic syndrome (Norris et al., 2011). Obesity is caused by fat accumulation in the liver through the following mechanism: Increased transport of fat or FAs from the intestine to the liver resulting in FA synthesis increases or decreases lipid oxidation in the mitochondria, both causing an increase in TG synthesis through the esterification process that occurs in the liver accompanied by a disruption of the release of TG from liver cells. The release of TG from liver cells depends on the bond with apoproteins, phospholipids, and cholesterol to form very low-density lipoprotein (VLDL) in the liver (Fabbrini et al., 2010).

There are several drugs that control obesity. Orlistat is a drug commonly used to control body weight (BW) combined with a caloric diet (Kakkar and Dahiya, 2015). There are two main categories of antiobesity drugs: agents that can reduce or limit energy absorption and reduce fat mass by increasing energy expenditure or redistributing adipose tissue (Chatzigeorgiou et al., 2014) and lipase inhibitors of the pancreas that can control weight (Kakkar and Dahiya, 2015). Inhibition of pancreatic lipase decreases free FAs and monoacylglycerol in the intestinal lumen and also decreases triacylglycerol to be absorbed, and orlistat is a drug that inhibits pancreatic lipase (Kang and Park, 2012).

Scenedesmus dimorphus as a nutraceutical because it contains active compounds that have the potential to be drugs and food supplements. Scenedesmus dimorphus contains pigments (betacarotene, astaxanthin, lutein, phycobiliprotein) as antioxidants. The insoluble fiber is the protective effect of heart, hepatoprotective, anti-inflammatory, and antihyperlipidemic (Gammone and D'Orazio, 2015; Hu et al., 2016). Lipid contains S. dimorphus (palmitic and oleic) and proteins with 18 types of amino acids (Armaini et al., 2016; Rinaldi et al., 2015). Scenedesmus dimorphus as a nutraceutical can repair bone marrow damage due to aplastic anemia. BW, red blood cells, hemoglobin, hematocrit values, and reticulocytes increased in anemia mice (Armaini et al., 2018).
Scenedesmus dimorphus contains beta-glucan, which is an active immunostimulator and has beneficial effects as a free radical scavenger, to reduce blood lipids (Chu et al., 2018). Omega-3, omega-6, poly-unsaturated fatty acid (PUFA), eicosa pentanoic acid (EPA), Docosa hexanoic acid (DHA), and alpha-linolenic acid (ALA) from lipid content, proteins, pigments, vitamins, and minerals reduce the effects of obesity and increase lipid metabolism (Arun et al., 2015; Chen et al., 2017). Nutraceuticals are intended for health and treat degenerative neurons in Alzheimer's disease, Parkinson's disease, heart disease, cancer, and other degenerative diseases, such as diabetes, obesity, and anemia. Omega-3 PUFA is the most widely used nutraceutical because it is useful in preventing and treating coronary heart disease, hypertension, diabetes, arthritis, autoimmune disorders, and cancer (Babcock and Helton, 2000; Howe, 2006; Mohan and Das, 2001; Schmidt et al., 2000). Consumption of omega-6 PUFA can reduce the incidence of deaths from $\mathrm{CV}$ disease including ischemic heart disease, nonischemic, myocardial heart disease, and hypertension (Afterburn et al., 2008). Handling obese sufferers can be done a consume dadih (traditional fermented milk products) specifically from Indonesia. Curd made from buffalo milk can improve health because it is rich in probiotics, as an antimicrobial, and can also be used as a diet for weight loss (Syukur et al., 2016). Some herbal products can be used to control hyperlipidemia. Ethyl acetate extract from Commiphora Mukul can reduce TG, total cholesterol (TC), and LDL-C and increase HDL-C in the treatment of hyperlipidemia and other related disorders such as atherosclerosis (Shaik and Khan, 2018).

Scenedesmus dimorphus contains omega-3 PUFA, which can inhibit VLDL secretion in the liver to decrease LDL production. This inhibition occurs because omega-3 can inhibit two main enzymes, diacylglycerol acyltransferase (DGAT) and phosphatidic acid phosphohydrolase (PA), which are involved in TG synthesis. Inhibition of liver enzymes causes a decrease in TG production and in the secretion of VLDL and LDL in the liver. Omega-3 can increase the oxidation of $\beta$ peroxisomes from FAs to reduce the availability of FA for TG synthesis, resulting in a reduction in liver fat (Jacobson, 2008). Based on the description above, this study aims to identify $S$. dimorphus as a useful drug for controlling obesity, which causes metabolic syndrome-linked NAFLD.

\section{MATERIALS AND METHODS}

\section{Experimental animals}

The research used adult mice (Mus musculus) as an experimental animal. Thirty mice were divided into six groups with body weighs between 20 and $30 \mathrm{~g}$ to obtain weight uniformity. Mice were acclimatized in the laboratory for 14 days and treated with a high-fat diet for 4 weeks to induce obesity $(\mathrm{BMI} \geq 30)$.

\section{Culture of Scenedesmus dimorphus}

Microalgae $S$. dimorphus was obtained from a collection of the Biochemical Laboratory, Department of Chemistry, Andalas University. This species was isolated from freshwater rivers in the city of Padang, Indonesia. Its morphological and molecular biology characteristics have been identified.

\section{Experimental design}

This study used a randomized block design consisting of six groups of five adult mice: group 1 normal control (NC) was 
given pellets and drinking water, group 2 obesity control (OC) was given a high-fat diet for four weeks until their BMI reached $\geq 30$ (Rohrer index), group 3 drug control (DC) obese rats were given orlistat orally once a day $(0.013 \mathrm{mg} / \mathrm{g} \mathrm{BW})$, and the remaining three groups of obese rats treated with $S$. dimorphus orally for 1 time a day, respectively consisting of $5 \mathrm{mg} / 20 \mathrm{~g}$ (group 4), $10 \mathrm{mg} / 20 \mathrm{~g}$ (group 5), and $15 \mathrm{mg} / 20 \mathrm{~g}$ body-weight (group 6). Observation of obese mice was carried out 7 and 21 days after treatment.

\section{Biomass production of Scenedesmus dimorphus}

Cultivation of $S$. dimorphus using bold basal medium (BBM) was carried out in a glass aquarium with a volume capacity of 20 L equipped with an aerator and a lamp with a light intensity of $50 \mu \mathrm{mol} \mathrm{m} \mathrm{m}^{-2} \mathrm{~s}^{-1}$ as light sources, with a ratio of 14:10 hours (light-dark). BBM with a modified source of nitrogen using urea (3 mM) (Rinaldi et al., 2015) was prepared and adding $S$. dimorphus culture into the medium. Scenedesmus dimorphus growth was observed every day and optical density was measured using a spectrophotometer at $550 \mathrm{~mm}$. Harvesting was done after two weeks, and biomass was separated by decantation for one day; after the biomass settled, the liquid medium was removed. Scenedesmus dimorphus biomass, which still contains liquid, was centrifuged $(3,000 \mathrm{rpm})$ to separate the supernatant, and the biomass was rinsed with distilled water three times until the biomass does not contain a medium. Freeze-dried biomass then crushed to obtain particles of 40-50 mesh size, and the dry biomass was stored at a refrigerator temperature of $-20^{\circ} \mathrm{C}$.

\section{Blood sampling}

Mice blood specimen was taken from the neck vein under deep anesthesia using a blood tube. The blood was then centrifuged $(5,000 \times \mathrm{g})$ for 30 minutes to separate the serum and erythrocytes. The blood serum was used for enzyme and lipid profile analysis.

\section{Lipid profile analysis}

Lipid profile, with test parameters consisting of TG, TC, LDL cholesterol, and HDL cholesterol, was determined using colorimetric methods with kits $\left(\right.$ Labtest $\left.^{\circledR}\right)$.

\section{Liver function analysis}

The enzymatic levels of alkaline phosphatase (ALP), aspartate aminotransferase (AST), and alanine aminotransferase
(ALT) were obtained out using the enzymatic method, also using a kit $\left(\right.$ Labtest $\left.^{\circledR}\right)$.

\section{Statistical analysis}

Data analysis was performed statistically using analysis of variance (ANOVA) (two factor with replication) in Microsoft Excel 2010. The results of the data are expressed as the average \pm standard deviation with the sample $(n=5)$ at $p<0.05(\alpha 0.05$ and power $=0.8$ ). The minimum sample size is calculated based on the value of $\mathrm{E}$, which is the degree of freedom of ANOVA. Any sample size, which keeps E between 10 and 20, should be considered as adequate (Charan and Kantharia, 2013; Ilyas et al., 2017). E can be measured by the following formula:

$E=$ Total number of animals - Total number of groups

Expected attrition or animal death: The final sample size must be adjusted to the expected attrition (Charan and Kantharia, 2013 ), in this study expecting a $10 \%$ reduction, then the sample size calculated by the formula or software should be divided by 0.9 to get the actual sample size.

\section{RESULTS}

\section{Analysis of obesity}

Induction of high-fat diet (HFD) causes mice to become obese after treatment for four weeks. BW and body length were measured every week to calculate BMI based on the Rõhrer index; mice are obese if their BMI value $\geq 30$. Induction of HFD on 25 mice caused obesity with a BMI between 44 and 46.8 .

\section{Analysis of lipid metabolism}

Obesity in mice can cause NAFLD, characterized by changes in lipid metabolism. Lipid profiles changed because of an increase in cholesterol and TG levels in the OC group after HFD administration compared with the $\mathrm{NC}$ group. Based on statistical test results, there are significant differences at $p<0.05$ with ANOVA (two factor with replication) after administration of $S$. dimorphus compared with $\mathrm{NC}$ and OC groups. The Duncan test determined differences between treatments from each group. An increase in total TG also occurred in obese mice with NAFLD compared to normal mice (Table 1). From day 7 to day 21, the DC group was given orlistat, which is usually provided to obese patients who have not been able to reduce cholesterol and TG levels. This is due to the use of orlistat as an inhibitor of pancreatic lipase to BW

Table 1. Measurements of Triglyceride and cholesterol in obese mice suffering NAFLD with the administration of $S$. dimorphus, NC, and OC at 7-21 days of observation.

\begin{tabular}{lcccc}
\hline \multirow{2}{*}{ Treatments } & \multicolumn{2}{c}{ TC (mg/dl) } & \multicolumn{2}{c}{ Total TG (mg/dl) } \\
\cline { 2 - 5 } & 7 Days & 21 Days & 7 Days & 21 Days \\
\hline NC & $87.9 \pm 1.521$ & $90.1 \pm 1.952^{*}$ & $120.7 \pm 3.642$ & $125.2 \pm 2.918^{*}$ \\
OC & $100.2 \pm 3.299$ & $108.7 \pm 1.863$ & $139.6 \pm 3668$ & $149.1 \pm 4.904$ \\
DC & $102.9 \pm 2.053$ & $123.1 \pm 1.221$ & $98.8 \pm 3.289$ & $127.3 \pm 4.031$ \\
$\begin{array}{l}\text { Obesity }+ \text { S. dimorphus } \\
(5 \mathrm{mg} / 20 \mathrm{mg} \text { BW })\end{array}$ & $131.6 \pm 2.192$ & $126.2 \pm 2.168$ & $134.6 \pm 2.359$ & $87.1 \pm 3.522$ \\
$\begin{array}{l}\text { Obesity }+ \text { S. dimorphus } \\
(10 \mathrm{mg} / 20 \mathrm{mg} \text { BW) }\end{array}$ & $104.0 \pm 3.742$ & $95.6 \pm 2.509$ & $115.3 \pm 3.606$ & $80.8 \pm 3.426$ \\
$\begin{array}{l}\text { Obesity }+ \text { S. dimorphus } \\
(15 \mathrm{mg} / 20 \mathrm{mg} \text { BW) }\end{array}$ & $110.3 \pm 5.318$ & $67.7 \pm 4.535^{*}$ & $124.4 \pm 3.641$ & $49.2 \pm 2.395^{*}$ \\
\hline
\end{tabular}

Data expressed mean $\pm \mathrm{SD}(n=5), \mathrm{SD} ;$ standard deviation, ${ }^{*} p<0.05$ 
control; overcoming obesity requires longer treatment time, and short-term use of the drug has not shown any benefits (Table 1).

Mice suffering from NAFLD experienced changes in their lipid profiles because of an increase in LDL cholesterol and a decrease in HDL cholesterol on day 21 compared with the NC group. Orlistat was able to reduce LDL cholesterol and increase HDL cholesterol levels compared with the OC but not to normal levels (Table 2). The results of the statistical test (ANOVA) at $p<0.05$ show a significant difference between treatments for the increase in HDL cholesterol. Further testing with Duncan test shows a significant $(p<0.05)$ increase in administering orlistat drugs and $S$. dimorphus on day 21 (Table 2).

\section{Effect of Scenedesmus dimorphus on lipid profile changes}

The administration of $S$. dimorphus in obese mice with NAFLD can reduce cholesterol and TG levels compared with the $\mathrm{OC}$ and $\mathrm{NC}$ groups on the 21 st day of observation. Based on statistical tests at $p<0.05$ with ANOVA, very significant intertreatment differences were seen with the administration of orlistat and $S$. dimorphus with an effective dose of $15 \mathrm{mg} / 20 \mathrm{~g} \mathrm{BW}$, compared with the OC group with NAFLD and the NC group. The administration of $S$. dimorphus at doses of $10 \mathrm{mg} / 20 \mathrm{~g} \mathrm{BW}$ and $15 \mathrm{mg} / 20 \mathrm{~g} \mathrm{BW}$ caused a decrease in TG levels on day 21, which is very drastic compared with those in the OC group with NAFLD and the DC group. Giving $S$. dimorphus to obese mice is more effective in reducing cholesterol and TG levels compared to giving orlistat (Table 1).

$S$. dimorphus can reduce LDL cholesterol levels compared to the OC, which is most effective at a dose of $15 \mathrm{mg} / 20$ $\mathrm{g} \mathrm{BW}$, which is close to the NC. The administration of orlistat (DC) in obese mice was seen to decrease LDL cholesterol levels, but cholesterol levels were still higher compared to the administration of $S$. dimorphus (Table 2). Based on the results of this study, it can be stated that the administration of $S$. dimorphus is more effective in lowering LDL cholesterol levels than orlistat (Table 2). The results of statistical tests showed that the decrease in LDL cholesterol was not significantly different in each treatment at $p<0.05$ (twofactor ANOVA with replication). The increase in HDL cholesterol occurred with the administration of $S$. dimorphus at an effective dose of $15 \mathrm{mg} / 20 \mathrm{~g} \mathrm{BW}$ compared to the $\mathrm{OC}$ and $\mathrm{NC}$ on day 21 . HDL cholesterol levels were above the $\mathrm{NC}$ but lower than the control for orlistat. Increasing HDL cholesterol levels by giving orlistat is better than through $S$. dimorphus. The statistical test showed that giving $S$. dimorphus and orlistat was significantly different at $p<0.05$ compared with the NC and obesity groups. Further testing with the Duncan test showed a very significant difference between giving $S$. dimorphus with a dose of $15 \mathrm{mg} / 20 \mathrm{~g} \mathrm{BW}$ and administering orlistat on the 21 st day of observation (Table 2).

\section{Analysis of liver function}

AST, ALT, and ALP enzyme activity is determined to observe decreased liver function. Induction of HFD in mice causes changes in lipid metabolism so that obese mice would have nonalcoholic fatty livers. NAFLD damages liver cells and reduces liver function. This is due to an increase in the release of liver enzymes and affects the increased enzyme activity of AST, ALT, and ALP in obese mice compared with those in the NC group at 7-21 days of observation. The relationship between BMI and AST, ALT and ALP activity looks very real, with increasing BMI, or the more fat the mice lead to an increase in liver enzyme activity (Fig. 1). Giving $S$. dimorphus can reduce mice weight (decrease in BMI value) and improve liver function by decreasing AST, ALT, and ALP enzyme activity (Fig. 1).

\section{Effect of Scenedesmus dimorphus on liver function}

The administration of $S$. dimorphus in obese mice can reduce the enzyme activity of AST, ALT, and ALP in all dose variations at 21 days of observation (Table 3 ). Observation on the seventh day showed no decrease in AST and ALT enzyme activity whereas ALP enzyme activity reduced. Statistical analysis with ANOVA from the testing of AST enzyme activity from obese mice showed a significant difference $(p<0.05)$ between each group given $S$. dimorphus compared to the NC and OC groups on observation days 7 to 21 (Table 3). Duncan's test was conducted to observe differences between treatments in all groups. Treatment with orlistat and $S$. dimorphus at a dose of $15 \mathrm{mg} / 20 \mathrm{~g} \mathrm{BW}$ showed a very significant difference compared to the $\mathrm{NC}$ and $\mathrm{OC}$ groups on the 21 st day of observation.

Table 2. Measurements of LDL-cholesterol and HDL-cholesterol in obese mice suffering NAFLD with the administration of S. dimorphus, NC, and OC at 7-21 days of observation.

\begin{tabular}{|c|c|c|c|c|}
\hline \multirow{2}{*}{ Treatments } & \multicolumn{2}{|c|}{ LDL-Cholesterol (mg/dl) } & \multicolumn{2}{|c|}{ HDL-Cholesterol(mg/dl) } \\
\hline & 7 Days & 21 Days & 7 Days & 21 Days \\
\hline $\mathrm{NC}$ & $8.9 \pm 0.63$ & $9.3 \pm 0.33$ & $50.2 \pm 1.99$ & $50.4 \pm 0.96$ \\
\hline $\mathrm{OC}$ & $25.0 \pm 3.95$ & $28.6 \pm 1.88$ & $48.7 \pm 0.87$ & $40.3 \pm 0.4$ \\
\hline DC & $18.5 \pm 1.52$ & $15.5 \pm 1.49$ & $64.6 \pm 1.07$ & $87.1 \pm 1.22 *$ \\
\hline $\begin{array}{l}\text { Obesity }+S . \text { dimorphus } \\
(5 \mathrm{mg} / 20 \mathrm{mg} \mathrm{BW})\end{array}$ & $14.3 \pm 1.88$ & $13.3 \pm 0.81$ & $80.4 \pm 1.02$ & $83.5 \pm 1.68$ \\
\hline $\begin{array}{l}\text { Obesity }+S . \text { dimorphus } \\
(10 \mathrm{mg} / 20 \mathrm{mg} \mathrm{BW})\end{array}$ & $13.1 \pm 1.97$ & $13.1 \pm 1.15$ & $63.8 \pm 0.84$ & $66.3 \pm 0.78$ \\
\hline $\begin{array}{l}\text { Obesity }+S \text {. dimorphus } \\
(15 \mathrm{mg} / 20 \mathrm{mg} \mathrm{BW})\end{array}$ & $13.1 \pm 1.23$ & $10.2 \pm 0.27$ & $87.7 \pm 0.89$ & $93.3 \pm 1.39 *$ \\
\hline
\end{tabular}


The statistical analysis of ALT enzyme activity test results from obese mice treated with orlistat and $S$. dimorphus with dose variation compared to $\mathrm{NC}$ and OC showed significant differences at $p<0.05$. Further testing with the Duncan test showed a very significant difference with the treatment of orlistat and $S$. dimorphus at a dose of $15 \mathrm{mg} / 20 \mathrm{~g} \mathrm{BW}$ on the $21 \mathrm{st}$ day of observation.

\section{DISCUSSION}

\section{Metabolic syndrome-related NAFLD}

The risk of NAFLD increased in association with obesity. The prevalence of NAFLD in mice increased with increasing BMI (Musso et al., 2009). Steatosis occurred as a characteristic of NAFLD when the absorption of liver FAs from plasma and de novo FA synthesis is greater than FA oxidation levels and the delivery of fat to the liver (as TG in VLDL). Therefore, the amount of excessive intrahepatic TG causes an imbalance between the complex interactions of FA metabolic events in conjunction with adipose tissue, liver, and systemic inflammation (Fabbrini et al., 2010). The administration of HFD causes fat levels in the body of mice to increase so that dyslipidemia occurs, accompanied by an increase in BMI.

\section{Effect of Scenedesmus dimorphus on lipid metabolism}

Based on the results, TG and cholesterol levels increased due to obesity (BMI 40-40.8) in experimental mice suffering from NAFLD due to HFD compared with those in NCs. The increase in TG and cholesterol levels in obese mice with NAFLD are caused by changes in lipid metabolism. NAFLD's association with highrisk dyslipidemia and HDL cholesterol levels is low (Chalasani et al., 2018). NAFLD with hepatic steatosis, in which large amounts of free FAs are released to the liver, thereby increasing liver TG synthesis and reducing the ability of the liver to secrete TG, can cause TG accumulation in hepatocytes (Musso et al., 2009; Yamashita et al., 2001). The administration of S. dimorphus can affect lipid metabolism because of the omega-3 content of $S$. dimorphus. The lipid content of PUFA from microalgae

\section{A. Obserbvation 7 days $\quad$ B. Observation 21 days}

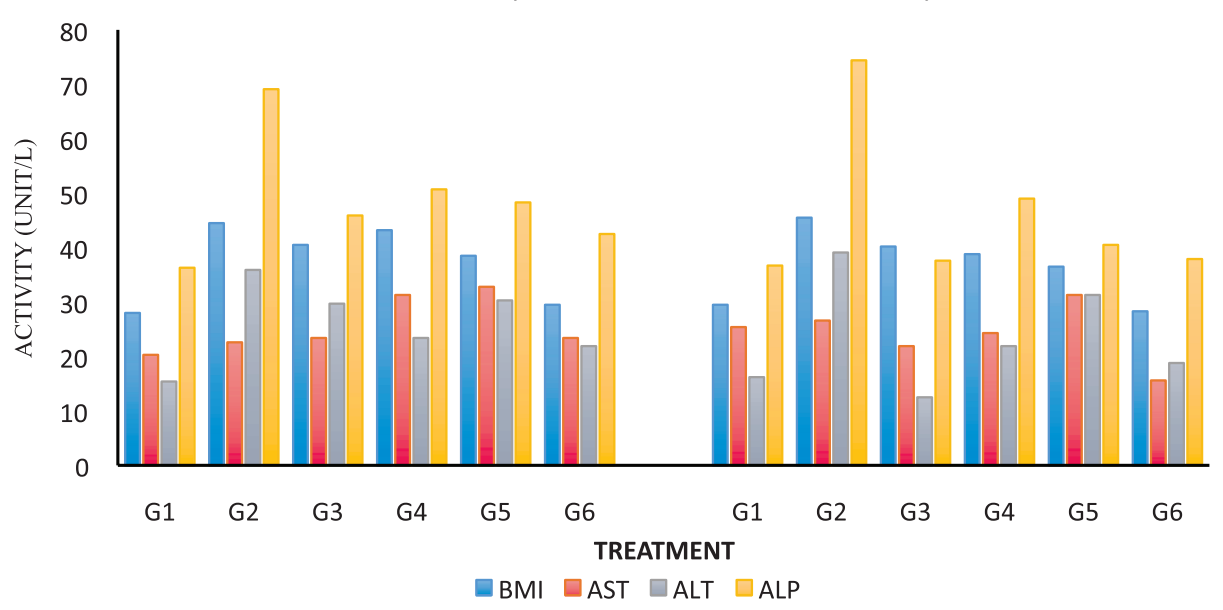

Figure 1. Relationship of BMI with AST, ALT, and ALP enzyme activity (Unit/L) in treatment G1 (NC), G2 (OC), G3 (DC), G4 (Obesity + Scenedesmus dimorphus 5 mg/20 g BW), G5 (Obesity + Scenedesmus dimorphus $10 \mathrm{mg} / 20 \mathrm{~g} \mathrm{BW}$ ), and G6 (Obesity + Scenedesmus dimorphus $15 \mathrm{mg} / 20 \mathrm{~g} \mathrm{BW}$ ) on observation ( $A=7$ days and $B=21$ days).

Table 3. Measurements of AST, ALT, and ALT activity on obese mice with treatments $S$. dimorphus

\begin{tabular}{|c|c|c|c|c|c|c|}
\hline \multirow{2}{*}{ Treatments } & \multicolumn{2}{|c|}{ AST (Unit/L) } & \multicolumn{2}{|c|}{ ALT (Unit/L) } & \multicolumn{2}{|c|}{$\operatorname{ALP}($ Unit/L) } \\
\hline & 7 days & 21 days & 7 days & 21 days & 7 days & 21 days \\
\hline Normal Cont (NC) & $20.3 \pm 0.41$ & $25.4 \pm 0.36$ & $15.4 \pm 0.29$ & $16.2 \pm 0.53$ & $36.3 \pm 0.46$ & $36.7 \pm 1.08$ \\
\hline Obesity Cont (OC) & $22.6 \pm 0.34$ & $26.6 \pm 0.37$ & $35.9 \pm 0.22$ & $39.1 \pm 0.49$ & $69.1 \pm 0.83$ & $74.4 \pm 0.82$ \\
\hline $\mathrm{DC}$ & $23.4 \pm 0.35$ & $21.9 \pm 0.27 *$ & $29.7 \pm 0.25$ & $12.5 \pm 0.38^{*}$ & $45.9 \pm 0.37$ & $37.6 \pm 0.83^{*}$ \\
\hline $\begin{array}{l}\text { Obesity }+S \text {. dimorphus } \\
(5 \mathrm{mg} / 20 \mathrm{mg} \mathrm{BW})\end{array}$ & $31.3 \pm 0.18$ & $24.3 \pm 0.25$ & $23.4 \pm 0.31$ & $21.9 \pm 0.39$ & $50.7 \pm 0.46$ & $49.0 \pm 0.83$ \\
\hline $\begin{array}{l}\text { Obesity }+S . \text { dimorphus } \\
(10 \mathrm{mg} / 20 \mathrm{mg} \mathrm{BW})\end{array}$ & $32.8 \pm 0.25$ & $31.3 \pm 0.31$ & $30.3 \pm 0.18$ & $31.3 \pm 0.49$ & $48.3 \pm 0.57$ & $40.5 \pm 0.38$ \\
\hline $\begin{array}{l}\text { Obesity }+S \text {. dimorphus } \\
(15 \mathrm{mg} / 20 \mathrm{mg} \mathrm{BW})\end{array}$ & $23.4 \pm 0.31$ & $15.6 \pm 0.32 *$ & $21.9 \pm 0.29$ & $18.8 \pm 0.37^{*}$ & $42.5 \pm 0.41$ & $37.9 \pm 0.29 *$ \\
\hline
\end{tabular}

Data expressed mean $\pm \mathrm{SD}(n=5), \mathrm{SD}$; standard deviation, ${ }^{*} p<0.05$, AST; Aspartate aminotransferase, ALT; Alanine aminotransferase, ALP; Alkaline phosphatase 
$S$. dimorphus shows an inhibitory effect on lipid accumulation in the liver. Inhibition of VLDL secretion occurs because omega-3 can inhibit two key enzymes, namely, DGAT and phosphatidic acid phosphohydrolase (PA), which are involved in the biosynthesis of TG in the liver, resulting in decreased TG production (Jacobson, 2008; Zhang and Lu, 2015), causing secretion of VLDL, and LDL in the liver also decreases. Omega-3 can increase peroxisome $\beta$-oxidation of FAs resulting in a decrease in the availability of FAs for TG synthesis so that there is a decrease in TG levels, cholesterol, and LDL cholesterol in the liver because of $S$. dimorphus, which can reduce NAFLD due to obesity (Jacobson, 2008; Ryeo-Eun et al., 2016).

The clinical effects of omega-3 FAs in reducing blood cholesterol levels are due to the omega-3 found in $S$. dimorphus influencing the mechanism of production of transport lipoprotein (VLDL and LDL) in the liver secreted into the blood. The high levels of VLDL and LDL can cause cholesterol deposits in the blood because VLDL and LDL are transport proteins that carry TG, cholesterol, and phospholipids from the liver to all tissues (Fabbrini et al., 2010). The administration of $S$. dimorphus with an effective dose of $15 \mathrm{mg} / 20 \mathrm{~g}$ BW can improve lipid metabolism to return to normal, reduce fatty liver in NAFLD cases, and increase HDL cholesterol, which plays a role in transporting cholesterol into the liver which is then broken down into bile acids and expelled through bodily excretion (Zhang and Lu, 2015).

\section{Analysis of liver function}

The administration of HFD causes mice to become fat because of the high-fat content and excess fat (triacylglycerol) stored in adipose. Fat accumulation in mice stomach can cause NAFLD; this can be predicted from an increase in liver enzyme secretion. The results of AST, ALT, and ALP tests showed an increase in liver enzyme activity in obese mice with BMI between 44 and 46.8. Liver enzyme activity of AST, ALT, and ALP in obese mice suffering from NAFLD increased compared to NCs on day 21 of observation. Obesity with a BMI $\geq 30$ can be used to predict an increase in liver enzyme levels, which are considered as a result of a fatty liver (Ruhl and Everhart, 2003), based on the results of studies that have found an increase in ALT, AST, and gamma-glutamyl transpeptidase levels due to alcohol, hypertension, and fatty liver (Stranges et al., 2005). Studies conducted on adolescents showed that $60 \%$ have high ALT levels due to being overweight or obese. In addition, about $1 \%$ of obese adolescents show ALT levels more than twice the normal (Strauss et al., 2000). Increasing ALT enzymes in liver toxicity is caused by loss of structural integrity of the liver. Giving orlistat can reduce the enzyme activity of AST, ALT, and ALP on the 21 st day of observation with a significant difference at $p<0.05$ and reaches almost normal conditions. Orlistat can inhibit pancreatic lipases and reduce or limit energy absorption to reduce fat mass by increasing energy expenditure (Chatzigeorgiou et al., 2014; Chen et al., 2017).

\section{Effect of Scenedesmus dimorphus on liver function}

Giving $S$. dimorphus can reduce the activity of AST, ALT, and ALP at an effective dose of $15 \mathrm{mg} / 20 \mathrm{~g}$ of BW; this is due to high levels of flavonoids and pigments in $S$. dimorphus which can act as antioxidants and have benefits in controlling the liver disease. According to a study conducted by Novilia et al. (2018), the content of flavonoids found in red betel leaves can be hepatoprotective. The high levels of antioxidants in S. dimorphus can repair liver cells damaged by the effects of NAFLD due to obesity. Flavonoids are anti-inflammatory and immunomodulatory agents (Fitriyani et al., 2011). Flavonoids can restore permeability and increase capillary vascular resistance (Benayache, 2014). Antioxidants from $S$. dimorphus are expected to reduce liver damage due to the binding of free radicals by antioxidant compounds. Free radicals will interfere with the integrity of the hepatocyte membrane, thus eliminating various enzymes from hepatocytes (Ryeo-Eun et al., 2016). Obesity can interfere with liver function due to NAFLD, which causes damage to liver cells, which then results in increased activity of the enzymes AST, ALT, and ALP (Das et al., 2015).

\section{CONCLUSION}

A high-fat diet causes obesity in mice with NAFLD. Obesity causes metabolic syndrome which then causes changes in the lipid profile such as decreased cholesterol, TG, and LDL cholesterol levels and an increase in HDL cholesterol. An effective dose of $S$. dimorphus $(15 \mathrm{mg} / 20 \mathrm{~g} \mathrm{BW})$ can reduce fat in hepatocytes from the liver of obese mice with NAFLD so that lipid metabolism becomes normal. NAFLD can cause decreased liver function, and administration of effective doses of $S$. dimorphus can reduce the activity of the enzymes AST, ALT, and ALP and improve liver function. Based on this study, it can be stated that $S$. dimorphus has potential as a nutraceutical because it can control obesity and can be used as a cure for NAFLD-linked metabolic syndrome.

\section{ACKNOWLEDGMENTS}

The authors are grateful to Andalas University, which has funded this research in accordance with the contract for the Professor Acceleration of research-publication clusters, Number 12/UN.16.17/PP.PGB/LPPM/2018 Budget Year 2018.

\section{CONFLICT OF INTEREST}

There are no conflicts of interest

\section{ETHICS COMMITTEE}

This study has obtained ethical clearance from The Committee of Research ethics of the Faculty of Medicine, Andalas University (registration number: 085/KEP/ FK/2018).

\section{REFERENCES}

Afterburn LM, Oken HA, Hall HB, Hamersley J, Kumiceko $\mathrm{CN}$, Hoffman JP. Algal-Oil capsules, and cooked salmon: N nutritionally equivalent sources of docosahexaenoic acid. J Am Diet Assoc, 2008; 108:1204-9.

Allen AM, Therneau TM, Larson JJ, Coward A, Somers VK, Kamath PS. Nonalcoholic fatty liver disease incidence and impact on metabolic burden and death: a 20 year- community study. Hepatol, 2018; 67(5):1726-36.

Alswat K, Aljumah AA, Sanai FM, Abaalkhail F, Alghamdi M, Al Hamoudi WK, Al Khathlan A, Al Quraishi H, Al Rifai A, Al Zaabi M, Babatin MA. Nonalcoholic fatty liver disease burden - Saudi Arabia and United Arab Emirates, 2017-2030. Saudi J Gastroenterol, 2018; 24:211-9.

Anderson EL, Howe LD, Jones HE, Higgins JPT, Lawlor DA, Fraser A. The prevalence of non-alcoholic fatty liver disease in children and adolescents: a systematic review and meta-analysis. PLOS One 2015; doi:10.1371/journal.pone.0140908

Armaini A, Salim M, Pribadi P. Induction effect of Scenedesmus dimophus against hematology on mice suffering anemia diseases. Asian J Pharm Clin Res, 2018; 11(7):348-52. 
Armaini A, Salim M, Rinaldi R. Influence of urea concentmiceion on biomass, pigment, lipid, and protein content of Scenedesmus dimorphus microalgae Der Pharma. Chemica J, 2016; 8(13).

Arun SK, Magnusson M, Leigh CW, Nicholas AP, Brown L. A green algae mixture of Scenedesmus and Schroederiella attenuates obesitylinked metabolic syndrome in mices. Nutrients, 2015; 7:2771-87.

Babcock T, Helton WS. Eicosapentaenoic acid (EPA): an antiinflammatory omega-3 fat with potential clinical. Nutrition, 2000; 16:11.

Benayache S. Hepatoprotective effect of Genista quadriflora Munby extract against ethanol-induced toxicity. Asian J Pharm Clin Res, 2014; 7:226-69.

Chalasani N, Younossi Z, Lavine JE, Charlton M, Cusi K, Rinella M, Harrison SA, Brunt EM, Sanyal AJ. The diagnosis, and management of nonalcoholic fatty liver disease: practice guidance from the American association for the study of liver diseases. Hepatology, 2018. 67(1), 328-57.

Charan J, Kantharia, ND. How to calculate sample size in animal studies? J Pharmacol Pharmacother, 2013; 4(4):303-6; doi:10.4103/0976500X.119726

Chatzigeorgiou A, Kandaraki E, Papavassiliou AG, Koutsilieris M. Peripheral targets in obesity treatment: a comprehensive update. Obes Rev, 2014; 15:487-503.

Chen SCC, Tsai SP, Jhao JY, Jiang WK, Tsao CK, Chang LY. Liver fat, hepatic enzymes, alkaline phosphatase, and the risk of incident type 2 diabetes: a prospective study of 132,377 adults. Scientific Reports, 2017; 7:4649.

Chu WL, Lim YW, Radhakrishnan AK, Lim PE. Protective effect of aqueous extract from Spirulina platensis against cell death induced by free radicals. BMC Complement Altern Med, 2010; 10:53-63.

Das AK, Chandra P, Gupta A, Ahmad N. Obesity, and the levels of liver enzymes (ALT, AST \& GGT) in East Medinipur, India. Asian J Med Sci, 2015; 6(1):40-2.

Dima A, Marinescu AG, Dima AC. Non-alcoholic fatty liver disease, and statins treatment. Rom J Intern Med, 2012; 50:19-25.

Fabbrini E, Sullivan S, Klein S. Obesity and nonalcoholic fatty liver disease: biochemical, metabolic, and clinical implications. Hepatology, 2010; 51(2):679-89; doi:10.1002/hep.23280

Fitriyani A, Winarti L, Muslichah S, Nuri N. Anti-inflammatory test of red betel leaf methanol extract (Piper crocatum Ruiz \& Pav) in white rats. Tradit Herbal Mag, 2011; 16:34-42.

Gammone MA, D'Orazio N. Anti-obesity activity of the marine carotenoid fucoxanthin. Mar Drugs, 2015; 13:2196-214.

Goyal NP, Schwimmer, MD. The progression and natural history of pediatric nonalcoholic fatty liver disease. Clin Liver Dis, 2016; 20(2):325-38

Howe PC. Dietary fats, and hypertension focus on fish oil. Ann New York Acad Sci, 2006; 827:339-52.

$\mathrm{Hu}$ X, Tao N, Wang X, Xiao J, Wang M. Marine-derived bioactive compounds with anti-obesity effect: a review. J Funct Foods, 2016; 21:372-87.

Ilyas MN, Adzim MKR, Simbak NB, Atif AB. Sample size calculation for animal studies using degree of freedom (E); an Easy and statistically defined approach for metabolomics and genetic research. Curr Trends Biomedical Eng \& Biosci, 2017; 10(2): CTBEB.MS.ID.555585.

Jacobson TA. Role of n-3 fatty acid in the treatment of hypertriglyceridemia, and cardiovascular disease. Am J of Clin Nutr, 2008; 87:1981S-90S

Ji C, Dai Y, Jiang W, Liu J, Hou M, Wang J, Burén J, Li X. Postnatal overfeeding promotes early onset, and exaggemiceion of highfat-diet-induced nonalcoholic fatty liver disease through disordered hepatic lipid metabolism in mices. J Nutr Biochem, 2014; 25:1108-16; doi:10.1016/j.jnutbio.2014.06.010

Kakkar AK, Dahiya N. Drug treatment of obesity: current status, and future prospects. Eur J Intern Med, 2015; 26:89-94.
Kang JG, Park CY. Anti-obesity drugs: a review of their effects, and safety. Diabetes Metab J, 2012; 36:13-25.

Le MH, Devaki P, Ha NB, Jun DW, Te HS, Cheung RC, Nguyen $\mathrm{MH}$. Prevalence of non-alcoholic fatty liver disease and risk factors for advanced fibrosis and mortality in the United States. PLOS One, 2017; https://doi.org/10.1371/journal.pone.0173499

Mohan K, Das UN. Prevention of chemically induced diabetes mellitus in experimental animals by polyunsatumiced fatty acids. Nutrition, 2001; 17(2):126-51.

Musso G, Gambino R, Cassader M. Recent insights into hepatic lipid metabolism in non-alcoholic fatty liver disease (NAFLD). Prog Lipid Res, 2009; 48:1-26.

Norris AL, Steinberger J, Steffen LM, Metzig AM, Schwarzenberg SJ, Kelly AS. Circulating oxidized LDL, and inflammation in extreme pediatric obesity. Obesity, 2011; 19:1415-9.

Novilia L, Harahap U, Anjelisa P, Hasibuan Z. Evaluation of the hepatoprotective effect of ethanolic extract from red betel (piper crocatum ruiz, and pav.) leaves. Asian J Pharm Clin Res, 2018; 11(7):248-250.

Rinaldi R, Armaini A, Salim M. A selection of nitrogen source for biomass, and lipid production of Scenedesmus dimorphus microalgae. Res J Pharm Biol Chem Sci, 2015; 6(3):143-7.

Ruhl CE, Everhart JE. A determinant of the association of overweight with elevated serum alanine aminotransferase activity in the United States. Gastroenterology, 2003; 124(1):71-9.

Ryeo-Eun G, Kyung AH, Geon TP, Lee MH, Lee GA, Kim CW, Jeon SY, Seo JW, Hong WK, Choi KC. Effects of microalgae polyunsatumiced fatty acid oil on body weight, and lipid accumulation in the liver of C57BL/6 mice fed a high-fat diet. J Biomed Res, 2016; 30

Schmidt EB, Skou HA, Christensen JH. Dyer-berg. N-3 fatty acids from fish, and coronary artery disease: implications for public health. J Public Health Nutr, 2000; 3(1): 91-8.

Shaik J, Khan Z. An antihyperlipidemic activity of Commiphora Mukul against atherogenic diet-induced hyperlipidemia in experimental mices. Asian J Pharm Clin Res, 2018; 11(6):386-9.

Stranges S, Trevisan M, Dorn JM, Dmochowski J, Donahue RP. Body fat distribution, liver enzymes, and risk of hypertension: evidence from the western New York study. Hypertension, 2005; 46(5):1186-93.

Strauss RS, Barlow SE, Dietz WH. Prevalence of abnormal serum transferase values in overweight, and obese adolescents. J Pediatr, 2000; 136(6):727-33

Syukur S, Aziz H, Fachrial E. Probiotic, and strong antimicrobial of buffalo milk fermentation (dadih) from different places in West Sumatera Indonesia. Res J Pharm Biol Chem Sci, 2016; 7(6):386-92.

WHO. Obesity, and overweight, World Health Organization, 2017.

Yamashita H, Takenoshita M, Sakurai M, Bruick RK, Henzel WJ, Shillinglaw W, Arnot D, Uyeda K. A glucose-responsive transcription factor that regulates carbohydmice metabolism in the liver. Proc Natl Acad Sci USA, 2001; 98:9116-21.

Zhang QQ, Lu LG. Non-alcoholic fatty liver disease: dyslipidemia, risk for cardiovascular complications, and treatment stmicegy Rev J Clin Trans Hepatol, 2015; (3):78-84.

How to cite this article:

Armaini A, Dharma A, Salim M. The nutraceutical effect of Scenedesmus dimorphus for obesity and nonalcoholic fatty liver disease-linked metabolic syndrome. J Appl Pharm Sci, 2020; 10(05):070-076. 